\title{
COMPUTER ETHICS: GENDER EFFECTS AND EMPLOYEE INTERNET MISUSE
}

\author{
Kimberly S. Young, St. Bonaventure University, kyoung@sbu.edu \\ Carl J. Case, St. Bonaventure University, ccase@ sbu.edu
}

\begin{abstract}
This article reports the findings of an empirical survey examining whether gender differences influence the degree to which individuals recognize unethical conduct in the use of information technology at work. Early research has primarily been limited to student samples and this study offers one of the first to examine the general population of Internet users. The results show no significant gender differences in the perception of unethical behavior in Internet use among the six ethical dilemmas presented. The ethical scenarios included personal use of the Internet, downloading music, viewing online pornography, visiting chat rooms, electronically sending jokes, and participating in cybersex. However, results suggest a disconnect between indicated degree of misuse and actual behavior in the workplace. This questions the effectiveness of Internet use policies. As a result, companies may need to do more to enforce or communicate policies, especially with regard to college graduates who enter the workforce, to mitigate the potential for employee Internet misuse.
\end{abstract}

Keywords: computer ethics, employee Internet misuse, ethics and gender, gender and technology

\section{INTRODUCTION}

Computer ethics is a relatively young discipline and few studies have examined the impact of gender on ethical decisions in information systems [1]. It is believed that gender differences exist as software piracy and hacking tend to be more prevalent among males than females [2].

Previous research on gender differences in ethical attitudes has been limited. In 1989, data from a sample of 213 business school students reveal that men are more than two times as likely as women to engage in actions regarded as unethical [4]. In 1995, a study specifically examining gender differences in the use of information technology found a significant gender gap in the recognition of unethical behavior [10]. Although this research found that female students were better able to recognize unethical actions described in information systems scenarios than male students, statistically significant differences varied depending upon the nature of the ethical dilemma presented. In 1996, another study found significant gender differences existed between male and female computer science majors in their ethical beliefs [11]. More recently, a study in 2006 found minimal gender differences in music downloading behavior, as $66 \%$ of male and $67 \%$ of female students did not view music downloading as stealing [5]. However, males spent twice as many minutes (112 minutes) than females (58 minutes) downloading music per day. Finally, in 2008, a study investigating the ethical awareness of computer use among undergraduate computer science students at two public Malaysian universities found minimal differences across gender, age and duration of computer use [12].

It has been argued that as more women enter the workforce it is important to understand how gender impacts the propensity for ethical behavior in the workplace [15]. It has also been suggested that gender makes a difference to ethical decisions in information technologies [2].

Furthermore, new concerns related to computer ethics have emerged as Internet usage continues to increase [8]. Employee Internet abuse issues relate to hacking, employee productivity, and corporate liability related to software piracy, especially regarding music and movie downloading, harassment suits, and inappropriate use [9]. These behaviors also raise questions about information privacy and security among employees and how ethical they are in protecting the integrity and accessibility of corporate data $[13,14]$.

Employee Internet abuse has forced companies to adopt acceptable Internet use policies to combat unproductive use of the computer [6]. Three-quarters of companies monitor employees' website connections in large part due to concern about inappropriate Internet surfing, according to a survey by the American Management Association (AMA) [3]. It is estimated that two-thirds of the US companies have an acceptable Internet Use Policy to combat employee misuse, yet the effectiveness of these policies have been questioned as a 2007 survey by the AMA found that over half of employees have been fired for email and Internet abuse [3]. The 28\% 
of employers who have fired workers for e-mail misuse did so for the following reasons: violation of any company policy $(64 \%)$; inappropriate or offensive language $(62 \%)$; excessive personal use $(26 \%)$; breach of confidentiality rules $(22 \%)$; and other $(12 \%)$.

As previous studies have relied upon student surveys, results have been less generalized to the general population of computer users. Therefore, this study examines the difference between student users and the general population of Internet users to determine if gender plays a role in computer ethics. Because there is an increasing reliance upon information technologies in the workplace, this study examined six ethical dilemmas pertaining to Internet use at work. To determine if gender differences exist in the likelihood of employee Internet abuse, scenarios related to activities such as downloading music at work, chatting at work, engaging in cybersex at work, and so on were utilized. As more women enter the workforce, the results will provide a greater perspective on how gender impacts ethical attitudes. This study also has important implications on the effectiveness of acceptable Internet use policies and employee compliance.

\section{RESEARCH DESIGN}

The study employs a survey research design. A webbased survey instrument that included six ethical dilemmas involving computer and Internet use was developed and was administered by the authors. Participants responded to the survey posted at the web site for the Center for Internet Addiction Recovery (www.netaddiction.com). Respondents were prompted to provide demographic information (age, gender) and minutes spent per week on various negative Internet activities such as viewing personal email at work, Internet gaming, viewing pornography, and so on. In addition, ethical scenarios assessed the user's perceptions of Internet misuse. Individuals rated the level of misuse from 0 (no misuse) to 7 (strong misuse). Survey data were converted into a computer-based database management system to improve the ease of tabulation and a program was written to summarize and filter data.

\section{RESULTS}

A sample of 451 usable surveys was obtained. Table 1 indicates that $46 \%$ of the respondents were male and $54 \%$ were female. The average age for males was 29 years. The average age for females was 28 years.

Volume X, No. 2, 2009
Table 1. Response Rate By Gender

\begin{tabular}{||c|r|r||}
\hline & Count & Percentage \\
\hline \hline Male & 209 & $46 \%$ \\
\hline Female & 245 & $54 \%$ \\
\hline Total & 451 & $100 \%$ \\
\hline
\end{tabular}

Table 2 details the age ranges of Internet users by gender. Males were generally young. Twenty-nine percent were less than 20 years, $33 \%$ were between 20 and 29 years, $14 \%$ were between 30 and 39 years, and $14 \%$ were between 40 and 49 years of age. A smaller portion were between 50 and 59 years $(5 \%)$ and $4 \%$ were over 60 years of age. Only $1 \%$ of male respondents did not provide their age. Females were also young with $23 \%$ less than 20 years, $29 \%$ were between 20 and 29 years, $16 \%$ were between 30 and 39 years, and $6 \%$ were between 40 and 49 years of age. Again, a smaller number of women were between 50 and 59 years $(5 \%)$ and only $2 \%$ were over 60 years of age. Nineteen percent of women respondents did not provide their age.

Table 2. Response Rate By Gender and Age

\begin{tabular}{||c|r|r||}
\hline \hline Age & \multicolumn{1}{|c|}{ Male } & \multicolumn{1}{c|}{ Female } \\
\hline \hline$<20$ years & $29 \%$ & $23 \%$ \\
\hline $20-29$ & $33 \%$ & $29 \%$ \\
\hline $30-39$ & $14 \%$ & $16 \%$ \\
\hline $40-49$ & $14 \%$ & $6 \%$ \\
\hline $50-59$ & $5 \%$ & $5 \%$ \\
\hline $60+$ & $4 \%$ & $2 \%$ \\
\hline Blank & $1 \%$ & $19 \%$ \\
\hline Total & $100 \%$ & $100 \%$ \\
\hline
\end{tabular}

Table 3 provides a breakdown of Internet activities categorized by gender. The most common activities identified by male respondents were personal email (78\% of respondents), instant messaging (59\%), online pornography $(58 \%)$, music downloading $(52 \%)$, and gaming $(51 \%)$ the most. Other activities used were chat rooms (22\%), online auctions (24\%), online shopping (24\%), stock watching $(8 \%)$, and Internet gambling $(6 \%)$. Females utilized personal email $(76 \%$ of respondents), instant messaging $(57 \%)$, and music downloading (47\%). Other activities used were gaming sites $(40 \%)$, online shopping $(31 \%)$, online auctions $(22 \%)$, chat rooms $(20 \%)$, stock watching $(5 \%)$ and Internet gambling $(4 \%)$.

Table 3. Internet Behaviors by Gender Issues in Information Systems 


\begin{tabular}{|l|c|c|}
\hline \multicolumn{1}{|c|}{ Online Activity } & Male & Female \\
\hline Chat Rooms & $22 \%$ & $20 \%$ \\
\hline Instant messaging & $59 \%$ & $57 \%$ \\
\hline Pornography & $58 \%$ & $18 \%$ \\
\hline Gambling & $6 \%$ & $4 \%$ \\
\hline Gaming & $51 \%$ & $40 \%$ \\
\hline Auction Houses & $24 \%$ & $22 \%$ \\
\hline Shopping & $24 \%$ & $31 \%$ \\
\hline Stock Watching & $8 \%$ & $5 \%$ \\
\hline Download Music & $52 \%$ & $47 \%$ \\
\hline Personal Email & $78 \%$ & $76 \%$ \\
\hline
\end{tabular}

Respondents were next given six ethics scenarios (Table 4) and prompted to rate each scenario on an 8point Likert-style scale with regard to the degree of misuse. The first ethical dilemma related to personal use of the Internet at work. The second scenario related to downloading music at work. The third scenario related to electronically distributing online jokes at work. The forth scenario related to downloading pornography at work. The fifth scenario related to using chat rooms at work. The sixth scenario related to using sex chat rooms and engaging in cybersex while at work.

\section{** Insert Table 4 here **}

Table 5 details the degree of the ethical attitudes by gender. Results indicate that over one-third (39\%) of males and one-third (38\%) of females feel that personal use of the Internet at work during lunch time is not misuse. Ninety-four percent of males and $91 \%$ of females indicated the misuse as low. Low relates to the rating range of 0 to 3 . In terms of downloading free music files at work, $4 \%$ of males and $4 \%$ of females indicated there was no misuse. Thirty percent of males and 35\% of females indicated the misuse as low. In terms of distributing electronic jokes, $10 \%$ of males and $10 \%$ of females indicated there was no misuse. Fifty-six percent of males and $51 \%$ of females indicated the misuse as low. In terms of downloading pornography at work, $6 \%$ of males and $5 \%$ of females indicated there was no misuse. Thirty-eight percent of males and 39\% of females indicated the misuse as low. In terms of visiting chat rooms at work, $22 \%$ of males and $17 \%$ of females indicated there was no misuse. Seventy-four percent of males and $77 \%$ of females indicated the misuse as low. In terms of engaging in cybersex at work, $7 \%$ of males and $6 \%$ of females indicated there was no misuse. Thirty-two percent of males and $37 \%$ of females indicated the misuse as low.

\section{** Insert Table 5 here **}

Table 6 examines gender differences among degree of misuse. Results showed that no significant differences were found between gender.

Table 6. Correlations

\begin{tabular}{|c|c|}
\hline Scenario & Pearson Chi Square \\
\hline 1 & .278 \\
\hline 2 & .012 \\
\hline 3 & .812 \\
\hline 4 & .892 \\
\hline 5 & .615 \\
\hline 6 & .405 \\
\hline
\end{tabular}

DISCUSSION

Results illustrate that the most common activities for male respondents were personal email $(78 \%$ of respondents), instant messaging (59\%), online pornography $(58 \%)$, music downloading $(52 \%)$, and gaming $(51 \%)$ the most. The least common activities used were chat rooms (22\%), online auctions (24\%), online shopping (24\%), stock watching (8\%), and Internet gambling (6\%). The most common activities for females were personal email $(76 \%$ of respondents), instant messaging (57\%), and music downloading $(47 \%)$. The lease common activities were gaming sites (40\%), online shopping (31\%), online auctions (22\%), chat rooms (20\%), stock watching $(5 \%)$ and Internet gambling $(4 \%)$.

This study also found similarities in attitudes among gender in the six ethical dilemma scenarios on workplace misuse. For example, 39\% of males and $38 \%$ of females indicated that personal use of the Internet at work during lunch time is not misuse. Similarly, $4 \%$ of males and $4 \%$ of females indicated there was no misuse in terms of downloading free music files at work. Moreover, $10 \%$ of males and $10 \%$ of females indicated there was no misuse in electronically distributing jokes. Overall, a Pearson Chi-Square test found no significant gender differences between responses.

Furthermore, results illustrate differing perceptions among the six ethical behaviors. When examining strong misuse (indicated degree of 5 though 7), the
Issues in Information Systems 
behaviors ranked as highest in perceived misuse are cybersex (62\% of males, $55 \%$ of females), music downloading (59\% of males, $58 \%$ of females), and viewing online pornography (52\% of males, $54 \%$ of females). The behaviors ranked lowest in misuse are sending jokes (30\% of males, $24 \%$ of females), chat room participation (17\% of males, $17 \%$ of females), and personal Internet use (3\% of males, $5 \%$ of females).

These results differ from previous studies utilizing student respondents. In terms of music downloading at work, a student study found that $66 \%$ of males and $67 \%$ of females indicated that was not misuse. In the current study, more than half of the male respondents $(59 \%)$ and more than half of the women $(58 \%)$ rated downloading music at work as a strong form of misuse.

There are three important implications from this study. First, it suggests that few gender differences exist in ethical attitudes among the general population of Internet users. Behaviors such as viewing pornography, music downloading, and engaging in cybersex at work were seen as strong forms of misuse among men and women. Both men and women also indicated that the personal use of the Internet during work hours, utilization of chat rooms during work hours, and sending electronic jokes at work were a low degree or non-misuse of work computers.

The second implication is that while most companies have acceptable Internet use policies, employees may not be adhering to them. The results strongly suggest that employees do not follow Internet use policies and that companies need to implement enforcement strategies to closely monitor employee Internet use. For example, while $59 \%$ of males and $58 \%$ of females perceive that music downloading is strong misuse, $52 \%$ of males and $47 \%$ of females indicate downloading music. In addition, while $52 \%$ of males perceive that viewing online pornography is strong misuse, 58\% of males indicate viewing online pornography. This is especially troublesome for companies because misuse behaviors such as downloading illegal or inappropriate material such as child pornography or copyright protected music/software files can result in corporate liability.

As findings reveal, both men and women are more open to using work computers for personal use such as checking stock quotes, doing online banking, and chatting online with friends. It has been noted that employee Internet abuse is on the rise despite the implementation of an acceptable Internet use policy.

Volume X, No. 2, 2009
Companies should be also clear about the types of computer behavior allowed among employees. Should all non-work related use be banned? Are certain times of the day acceptable times for personal online use say during lunch hours or after work?

The third implication is that perhaps Internet use policies are not being properly communicated. It is a common practice that employees must sign an acknowledgement that they have read an acceptable Internet use policy, but it may be that without continual reinforcement of the policy, it is easily forgotten. This may be especially important as younger individuals enter the workforce and as previous findings suggest, college students tend to have a more permissive perspective relative to Internet behavior at work than do the general population of Internet users.

The limitations of this study are primarily a function of the sample, sample size and type of research. Although responses were relatively equally distributed among gender, a larger sample size, more equal gender distribution of respondents, and use of additional measures would increase the robustness of results. Implementation of the survey at additional web portals, other than the current Internet addiction/recovery web site, would also increase generalizability. Another limitation relates to the self-reported nature of the survey.

Future research should examine how companies update their Internet use polices to stay current with new technologies in the workplace. For instance, a firm moves from Intranet-based email access to a wireless system, supplying employees with Blackberry devices to access web accounts. Employees may engage in more ethical misuse given the greater accessibility to the Internet and limited monitoring of portable devices. The company must then modify its Internet acceptable use policies to incorporate these new applications. However, companies often upgrade workplace technologies without updating policies, leaving themselves at great corporate risk if an employee abuses the new technologies and no policy specifically mandates its misuse.

Future research should also be directed at what personality factors may influence the ethical behavior and gender differences. In addition, more scenarios with diverse ethical implications will assist in further exploring behavior. Overall, the current results and future research will assist information system managers in developing better policies for employees to act in ethical manner with regard to information
Issues in Information Systems 
technology within the scope of their work and employment.

\section{REFERENCES}

1. Adams, A., and Oforni-Amanfo, J. (2000). Does gender matter in computer ethics? Ethics and Information Technology. 2(1): $37-47$.

2. Adams, A. (2000). Gender and computer ethics. ACM SIGCAS Computers and Society. 30(4): 17-24.

3. American Management Association (February 28, 2008). 2007 Electronic Monitoring \& Surveillance Survey: Over half of all employers combined fire workers for email and Internet abuse. Accessed on February 27, 2009 at http://press.amanet.org/pressreleases/177/2007-electronic-monitoringsurveillance-survey/

4. Betz' M., O'Connell, L. \& Shepard, J. M. (1989). Gender differences in proclivity for unethical behavior. Journal of Business Ethics. 8 (9): 321-324.

5. Case, C. J. \& Young, K.S. (2006). A gender analysis of student music downloading behavior and ethics effectiveness. Proceedings of the American Society of Business and Behavioral Sciences, 10.1, Las Vegas, NV, February 23-26.

6. Case, C. J. \& Young, K.S. (2002). Employee Internet Use Policy: An Examination of Perceived Effectiveness. Issues in Information Systems. 3(1): 82-88.

7. Case, C. J. \& Young, K. S. (2002). Employee Internet Management: Current Business Practices and Outcomes. Cyberpsychology and Behavior. 5(4): 355361 .

8. Conger, S. and Loch, K.D. (2001) Invitation to a Public Debate on Ethical Computer Use. The Database for Advances in Information Systems. 32(1): 16-17.

9. Johnson, J. J and Ugray, Z. (2007). Employee Internet abuse: policy versus reality. Issues in Information Systems. 8(2): 214-219.

10. Khazanchi, D. (1995). Unethical behavior in information systems: The gender factor. Journal of Business Ethics. 14(9): 741-749.

11. Loch, K. D. and Conger, S. (1996). Evaluating ethical decision making and computer use. Communications of the ACM. 39(7): 74-83.
12. Masrom, M., Ismail, Z. \& Hussein, R. (2008) Computer Ethics Awareness Among Undergraduate Students in Malaysian Higher Education Institutions. Paper presented at the 19th Australian Conference on Information Systems, December 3, 2008.

13. McCarthy, R.V., Halawi, L., \& Aronson, L. (2005). Information Technology Ethics: A Research Framework. Issues in Information Systems. 4(2): 64-69.

14. Thompson, P. (2001). Privacy, secrecy, and security. Ethics and Information Technology. 3(1):13-19.

15. Quigley, B. Z and Mohamad, S. (2008). Gender, the propensity for ethical behavior and the bottom line. Journal of Business and Behavioral Sciences. 19(20):46-57. 
TABLE 4

Ethical Scenarios

\begin{tabular}{||ll||}
\hline \hline 1 & $\begin{array}{l}\text { Chris uses the Internet at work during lunch hour to check stocks, transfer money at the bank, and } \\
\text { write letters to friends. Chris gets positive employee evaluations because Chris completes job } \\
\text { responsibilities as required by the company. }\end{array}$ \\
\hline 2 & $\begin{array}{l}\text { Robin uses KaZaa at work to download music files. Robin believes that playing music at work } \\
\text { improves productivity and relieves stress. }\end{array}$ \\
\hline 3 & $\begin{array}{l}\text { Fran is the office clown and enjoys a good laugh. Whenever Fran receives a joke, Fran distributes } \\
\text { the joke electronically to friends and co-workers. }\end{array}$ \\
\hline 4 & $\begin{array}{l}\text { Pat travels one week per month for the company. During travel, the company provides Pat with a } \\
\text { notebook computer and Internet access so that Pat can perform job responsibilities. After } 7 \text { p.m., one } \\
\text { lonely evening, Pat downloads pornography. }\end{array}$ \\
\hline 5 & $\begin{array}{l}\text { Jan is a professor at the local university. Jan teaches a class entitled "Psychology of the Internet." Jan } \\
\text { regularly visits chat rooms while at the university. }\end{array}$ \\
\hline 6 & $\begin{array}{l}\text { Dr. Jones is a physician. While at the hospital, Dr. Jones engages in cybersex with Kelly. Kelly is } \\
\text { Dr. Jones' spouse and a lab assistant at the same hospital. }\end{array}$ \\
\hline
\end{tabular}

TABLE 5

Degree of Misuse by Gender

\begin{tabular}{|c|c|c|c|c|c|c|c|c|c|}
\hline Dilemma & $\begin{array}{l}\text { Internet Misuse } \\
0=\text { No misuse } \\
7=\text { Strong misuse }\end{array}$ & 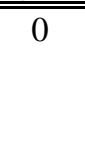 & $\bar{~} 1$ & 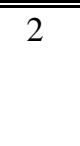 & "3 & 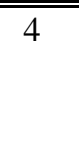 & 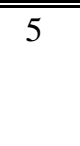 & $\bar{~} 6$ & $\overline{77}$ \\
\hline 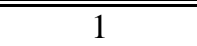 & Males & $39 \%$ & $29 \%$ & $11 \%$ & $15 \%$ & $2 \%$ & $2 \%$ & $1 \%$ & $0 \%$ \\
\hline Personal use & Females & $38 \%$ & $22 \%$ & $9 \%$ & $22 \%$ & $3 \%$ & $2 \%$ & $1 \%$ & $2 \%$ \\
\hline 2 & Males & $4 \%$ & $5 \%$ & $7 \%$ & $14 \%$ & $11 \%$ & $17 \%$ & $20 \%$ & $22 \%$ \\
\hline Music & Females & $4 \%$ & $3 \%$ & $4 \%$ & $24 \%$ & $7 \%$ & $17 \%$ & $13 \%$ & $28 \%$ \\
\hline 3 & Males & $10 \%$ & $9 \%$ & $10 \%$ & $27 \%$ & $15 \%$ & $15 \%$ & $9 \%$ & $6 \%$ \\
\hline Jokes & Females & $10 \%$ & $10 \%$ & $10 \%$ & $31 \%$ & $14 \%$ & $12 \%$ & $5 \%$ & $7 \%$ \\
\hline 4 & Males & $6 \%$ & $4 \%$ & $6 \%$ & $22 \%$ & $10 \%$ & $8 \%$ & $9 \%$ & $35 \%$ \\
\hline Pornography & Females & $5 \%$ & $5 \%$ & $6 \%$ & $23 \%$ & $7 \%$ & $7 \%$ & $11 \%$ & $36 \%$ \\
\hline 5 & Males & $22 \%$ & $14 \%$ & $12 \%$ & $26 \%$ & $10 \%$ & $6 \%$ & $8 \%$ & $3 \%$ \\
\hline Chat rooms & Females & $17 \%$ & $17 \%$ & $10 \%$ & $33 \%$ & $8 \%$ & $6 \%$ & $7 \%$ & $4 \%$ \\
\hline 6 & Males & $7 \%$ & $4 \%$ & $4 \%$ & $17 \%$ & $6 \%$ & $11 \%$ & $12 \%$ & $39 \%$ \\
\hline Cybersex & Females & $6 \%$ & $3 \%$ & $3 \%$ & $25 \%$ & $9 \%$ & $9 \%$ & $12 \%$ & $33 \%$ \\
\hline
\end{tabular}

